\title{
BMJ Open Evaluating a multicomponent survivorship programme for men with prostate cancer in Australia: a single cohort study
}

\author{
Patsy Yates (D) , ${ }^{1}$ Rob Carter, ${ }^{2}$ Robyn Cockerell, ${ }^{1}$ Donna Cowan, ${ }^{3}$ Cyril Dixon, ${ }^{3,4}$ \\ Anita Lal, ${ }^{2}$ Robert U Newton (D) , ${ }^{5,6}$ Nicolas Hart, ${ }^{1,5}$ Daniel A Galvão (D) , \\ Brenton Baguley, ${ }^{6,7}$ Nicholas Denniston, ${ }^{8}$ Tina Skinner, ${ }^{6}$ Jeremy Couper, ${ }^{9}$ \\ Jon Emery (D) , ${ }^{10}$ Mark Frydenberg, ${ }^{11}$ Wei-Hong Liu (i) ${ }^{1}$
}

To cite: Yates $\mathrm{P}$, Carter $\mathrm{R}$, Cockerell R, et al. Evaluating a multicomponent survivorship programme for men with prostate cancer in Australia: a single cohort study. BMJ Open 2022;12:e049802. doi:10.1136/ bmjopen-2021-049802

- Prepublication history and additional supplemental material for this paper are available online. To view these files, please visit the journal online (http://dx.doi.org/10.1136/ bmjopen-2021-049802).

Received 03 February 2021 Accepted 12 January 2022

Check for updates

(C) Author(s) (or their employer(s)) 2022. Re-use permitted under CC BY-NC. No commercial re-use. See rights and permissions. Published by BMJ.

For numbered affiliations see end of article.

Correspondence to Professor Patsy Yates; p.yates@qut.edu.au

\section{ABSTRACT}

Objective To evaluate the implementation of a multicomponent survivorship programme for men with prostate cancer and their carers.

Design A single cohort study, guided by the RE-AIM framework.

Setting Multiple health services in Australia.

Participants Men with prostate cancer and their carers, and health professionals.

Intervention A 12-month telehealth programme that provided centralised and coordinated decision and information support, exercise and nutrition management, specialised clinical support and practical support to men and their carers.

Data collection Multiple sources of data including participant-reported health outcomes and experience of care, qualitative interviews, records of the programme were collected at different time points.

Results Reach: Of 394 eligible men at various stages of survivorship, 142 consented (36\% consent rate) and 136 (96\%) completed the programme. Adoption: All men participated in general care coordination and more than half participated in exercise and/or nutrition management interventions. Participation in the specialised support component (ie, psychosocial and sexual health support, continence management) was low despite the high level of need reported by men. Effectiveness: Overall, the men reported improvements in their experience of care. Implementation: Factors such as addressing service gaps, provision of specialised services, care coordination, adoption of needs-based and telehealthbased approaches were identified as enablers to the successful implementation of the programme. Issues such as insufficient integration with existing services, lack of resources and high caseload of the intervention team, men's reluctance to discuss needs and lack of confidence with technology were barriers in implementing the programme.

Conclusion Survivorship interventions are relevant to men regardless of the stage of their disease and treatments undertaken. It is possible to provide access to a comprehensive model of survivorship care to promote the health and quality of life for men with prostate cancer.
Strengths and limitations of this study

- This is one of the only studies that have evaluated the implementation of multicomponent survivorship interventions for men with prostate cancer and their carers.

- Applying the RE-AIM framework, this study has assessed the Reach, Effectiveness, Adoption and Implementation of the intervention.

- This study is limited by the absence of a comparison group to determine efficacy. Nonetheless, the multiple sources of data collected provide support for continuing to build on the principles and components of such model of care.

Trial registration number This study was registered with the Australian and New Zealand Clinical Trials Registry (ACTRN12617000174381).

\section{INTRODUCTION}

Ongoing advances in prostate cancer diagnosis and treatment, combined with population ageing, have resulted in continued growth in the number of prostate cancer survivors across many high-resource countries. ${ }^{1-3}$ Many survivors experience a range of disease and treatment related symptoms that negatively impact physical, psychosocial and social functioning. Frequently reported short-term and long-term unmet needs relate to sexual health and relationships, urinary incontinence, informational, physical and psychological needs. ${ }^{4-6}$ However, the evidence base for supportive care interventions to address these needs is limited. One Cochrane review ${ }^{7}$ of the effectiveness of psychosocial interventions for men with prostate cancer has highlighted the potential for such care, concluding that men who received psychosocial intervention had a 
small but short-term improvement in their physical and cancer-related quality of life and prostate cancer knowledge.

In response to gaps in survivorship care for men with prostate cancer, Movember (a global charity organisation) developed a global programme (known as TrueNTH) seeking to design, implement and evaluate survivorship interventions across a number of countries. In Australia, the Movember team designed an integrated multicomponent survivorship programme for men with prostate cancer and their carers. ${ }^{8}$ This care model was focused on addressing gaps in existing programmes that indicated that most to date had focused on single prostate cancer symptoms or side effects or a single intervention approach. It was based on recommendations from cancer survivorship models ${ }^{910}$ that highlight the benefits of integrated approaches and risk stratification to enable interventions to be delivered according to need, thereby ensuring both person centred care as well as efficient use of scarce health resources. The importance of engaging primary care services for follow-up survivorship care after the acute treatment phase is also recommended to ensure long-term adverse effects are addressed.

The resulting programme involved core components of care coordination, information provision, decision support, self-management, exercise and nutrition management, as well as referral to specialised services (continence advice, sexual health counselling and psychological support) where required. The programme was successfully evaluated in a feasibility study ${ }^{11}$ involving 51 men and 13 carers, which confirmed that it was accepted by men, largely implemented as per protocol, and that the proposed evaluation procedures were acceptable and feasible for men across all stages of disease. In this paper, we report findings from a larger scale study designed to evaluate the implementation of the programme across multiple services throughout Australia. Specifically, this study uses the RE-AIM framework ${ }^{12}$ to assess the reach, effectiveness, adoption, implementation and maintenance of the programme.

The objectives of the study were to: (1) describe the nature and scope of the programme and how it was implemented in various healthcare contexts in terms of the reach of the programme to different populations, adoption of intervention components and consistency and adaptations made to the interventions; (2) evaluate the impact of the programme on men's prostate health symptoms, psychological distress, experience of care and health behaviour; (3) identify contextual factors influencing the implementation of the programme in terms of health system and health professional issues, patient and carer factors and sustainability of the programme and (4) conduct a comprehensive cost analysis of the programme.

In this paper, we report findings relating to the first three objectives only. Findings relating to cost analysis and the broader economic evaluation incorporating the quality-of life instrument (EQ-5D-5L) will be reported elsewhere.
MATERIALS AND METHODS

\section{Study design}

This study involved a single group design with prospective assessment at different time points over a 12-month period, whereby all consented men and their partner/ carer were enrolled in the programme. A mix of quantitative and qualitative data were collected from a range of sources to address the elements of the RE-AIM framework.

\section{Setting and sample}

Four public hospitals and five private health services in Victoria, Queensland, Northern Territory and South Australia participated in the programme. Men who had been diagnosed with prostate cancer were eligible if they were receiving services from any of the participating sites. Men were excluded from the study if they were too unwell (as determined by their treating specialist), or had physical, psychological or cognitive difficulties that would prevent them from participating in the study. The treating specialists (eg, urologist, radiation or medical oncologist) or nominated clinical contact at sites identified potential participants and referred them to the research team at the coordinating university (QUT) for consent after gaining permission from the man for the referral. Written consent was sought for participation in the study, with a separate optional consent for access to their individual healthcare data (to be reported separately) from the Department of Human Services for the purpose of economic evaluation.

The referring specialists were informed about the man's participation in the study. All consented men were also asked to nominate a general practitioner (GP) to be part of his care team. In addition, they were asked if they wished to nominate a partner/carer. Written consents were obtained from the nominated partner/carer.

Key clinicians of the treating team, TrueNTH service providers and Movember representatives were also invited to take part in the evaluation of the programme. Written consents were obtained from these staff.

\section{The Australian TrueNTH programme}

The programme delivered a multicomponent integrated model of care to men with prostate cancer that is illustrated in figure 1.

\section{Features of intervention delivery}

The key features of the model included care that was coordinated by a single point of contact who was a registered nurse (care coordinator) with experience in urology and/or prostate cancer nursing. Prior to site initiation, the Coordinator engaged with each site and conducted a scoping exercise to identify key support services and resources provided for men with prostate cancer and their carers by local health and community service providers. To ensure a consistent standard of delivery for the components of the intervention, Movember engaged expert service providers with experience in prostate cancer to provide centralised services that complemented 


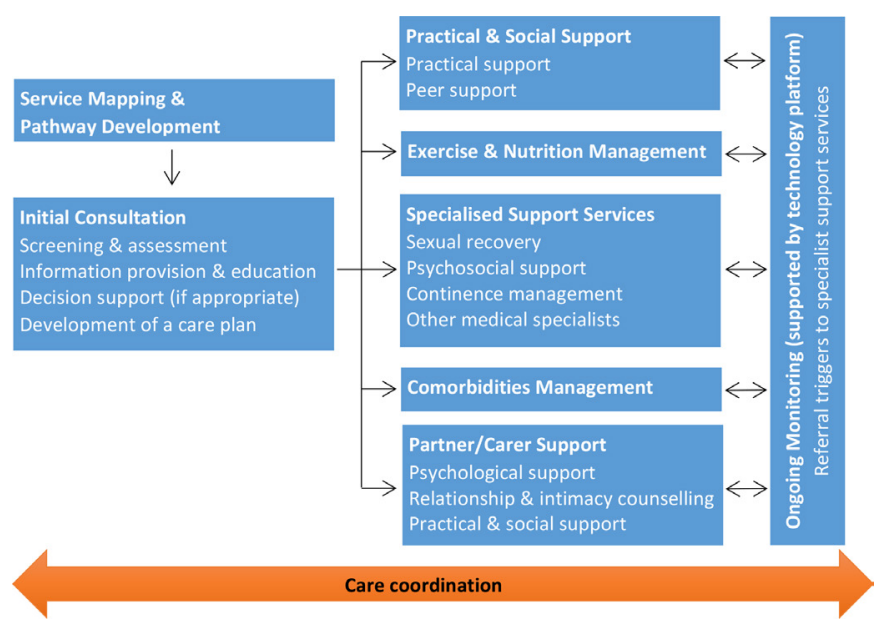

Figure 1 TrueNTH care model.

local services where relevant. All centralised services were delivered remotely using telephone, mobile phone or video conference.

Men were allocated, based on their stage of prostate cancer and treatment received at enrolment, to one of five care pathways (as shown in table 1) developed for the intervention based on findings from the feasibility study. An online care management tool (cdmNet (It is now called Inca)) was used to manage and support care planning, delivery and review of the services by all members of the care team throughout the care continuum. Men were provided with this tool, which enabled them to access their individualised care plan and undertake ongoing self-monitoring of their symptoms and needs on a 3 monthly basis or when new symptoms emerged. An alert was sent to the Coordinator and GP when patient assessments were completed. If the man did not want to use the tool to communicate with the care team or access information, hard copies of information and the care plan were provided.

\section{Intervention components}

\section{Information, education and decision support}

At enrolment, the Coordinator remotely conducted a comprehensive assessment with each man to assess his prostate cancer-specific symptoms, as well as their general and psychological health, nutrition status and supportive care needs. Men were provided with an evidence-based education package and decision support material relevant to their stage of disease and treatment. The outcome of the assessment was communicated to the man's treating specialist/team and GP via email or mail. This information provided the basis for development of a care plan and referrals to appropriate specialist support services according to the men's health needs and preferences, preference of treating specialist/team and the availability of local resources. Moreover, the Coordinator liaised with the man's GP to facilitate additional assessments for risks of conditions or management of comorbidities, such as osteoporosis, cardiovascular disease, obesity and diabetes. Based on the assessment, the GP liaised with the treating team to facilitate the management of any identified risk factors and conditions.

All men were also provided with information about peer support programmes and referred to relevant

Table 1 Definition of TrueNTH care pathway and data collection points

\begin{tabular}{|c|c|c|c|c|c|c|}
\hline \multirow{2}{*}{$\begin{array}{l}\text { Allocated } \\
\text { subgroups }\end{array}$} & \multirow[b]{2}{*}{ Definition } & \multirow{2}{*}{$\begin{array}{l}\text { Preintervention } \\
\text { T0 }\end{array}$} & \multicolumn{4}{|c|}{ After enrolment in the intervention } \\
\hline & & & T1 & T2 & T3 & T4 \\
\hline $\begin{array}{l}\text { Active } \\
\text { surveillance }\end{array}$ & $\begin{array}{l}\text { Men with localised prostate } \\
\text { cancer who were undergoing } \\
\text { active surveillance }\end{array}$ & At enrolment & 3 months & 5 months & 8 months & 12 months \\
\hline $\begin{array}{l}\text { Radiation } \\
\text { therapy }\end{array}$ & $\begin{array}{l}\text { Men with localised prostate } \\
\text { cancer who were undergoing } \\
\text { radiation therapy }\end{array}$ & At enrolment & / & 5 months & 8 months & 12 months \\
\hline Surgery & $\begin{array}{l}\text { Men with localised prostate } \\
\text { cancer who were undergoing } \\
\text { surgery or completed surgery no } \\
\text { more than } 3 \text { months }\end{array}$ & At enrolment & 3 months & 6 months & 9 months & 12 months \\
\hline $\begin{array}{l}\text { Treatment } \\
\text { completed }\end{array}$ & $\begin{array}{l}\text { Men with localised prostate } \\
\text { cancer who had completed } \\
\text { primary treatment }\end{array}$ & At enrolment & 3 months & 6 months & 9 months & 12 months \\
\hline
\end{tabular}

/ indicates no data collection occurred at the time. 
support services to address their needs relating to transport, accommodation, finance, legal, employment and respite services for carers, as required.

\section{Exercise and nutrition management}

All men were referred to a centralised accredited exercise physiologist (AEP; Exercise and Sport Science Australia) and received an evidence-based exercise prescription regardless of their stage of disease, or their past, current, or future treatments, financial capacity or geographical location. This prescription was tailored to each man to address the specific issues causing the greatest concern, or to prepare for future treatments, or to address post-treatment issues. The service was delivered remotely by one service provider through multiple modes, including phone or online teleconferences, DVD, online or paper materials, with referral to local exercise physiology services depending on available resources in their geographical location. All men were also referred to dietetic services either locally or through a centralised service using accredited practising dietitians (APD; Dietitians Australia). Men underwent a comprehensive nutritional assessment with the dietitian and received an individualised nutrition prescription tailored to their stage of disease, treatment plan, treatment-related side effects, gastrointestinal tolerance/allergies, financial capacity and geographical location. The dietetic intervention was designed to improve diet quality and reduce weight gain and other prominent side effects of prostate cancer treatment. For men who were malnourished, or undergoing chemotherapy or radiotherapy, standardised evidence-based guidelines were implemented to reduce nutritional impact, symptoms of treatment, maintain oral intake and reduce wasting of muscle mass and total body mass. ${ }^{13}$

\section{Specialised services}

The Coordinator referred men to various specialised clinical supports at any point during the intervention. These services were delivered remotely by a specialist service engaged for the purposes of this project, which included sexual health support, providing a range of sexual rehabilitation interventions in relation to physical functioning and erectile rehabilitation, psychosexual, intimacy and relationship functioning according to individual needs and risk factors. Psychological support services were also available. Men with mild anxiety or depression were referred to an online self-management programme developed by the service providers, while those identified with moderate or high anxiety and/or depression or other mental health concerns were referred to a psychiatrist or psychologist with expertise in prostate cancer, or cancer in general. Men could also be referred to continence management services if required.

\section{Partner and carer support}

Partners and carers were encouraged to participate in the programme. The Coordinator provided them with support as appropriate, which included provision of required information, referrals to services for emotional and general well-being concerns, as well as intimacy and relationship counselling.

\section{Data collection and measurements}

Reach, adoption and implementation of the intervention

The research team at QUT maintained administrative records of referrals, eligibility screening, reasons for declining participation and the retention rates. Participant demographics were collected. The referring specialists provided clinical information of consented men at enrolment, including cancer stage, grade, date of diagnosis, treatment received, comorbidities, prostate-specific antigen level or other relevant test results (eg, CT/MRI scans, X-rays). Information on intervention delivery and attendance was documented by the intervention team and captured by cdmNet. In addition, individual telephone interviews were conducted with selected men and carers (by their care pathway, residence area, source of referral) after 6 months following enrolment in the intervention to explore their experiences of prostate cancer and care, ongoing unmet needs, and experiences with the programme. Interviews were also conducted with consented clinicians, TrueNTH service providers and Movember representatives towards the end of the study to provide insights into factors influencing the implementation of the intervention. Furthermore, an audit of progress notes and assessment records recorded on cdmNet using a structured checklist was undertaken by a research assistant not involved in delivery of the intervention. The purpose of the audit was to objectively evaluate adherence and compliance to the study protocol in relation to referral to centralised exercise and nutrition management services.

\section{Effectiveness of the intervention}

Depending on the allocated care pathway at enrolment, up to five surveys (as shown in table 1) were collected from the men and carers via post or online. Each survey consisted of two questionnaires: the health outcome questionnaire and the health service utilisation questionnaire (the economic evaluation will be reported separately).

The following health outcomes were assessed to explore the changes over the intervention period using validated instruments:

\section{Prostate cancer-specific quality of life}

The Expanded Prostate Cancer Index short form (EPIC26) ${ }^{14}$ was used to measure prostate cancer-specific symptoms in relation to urinary incontinence, urinary irritation/obstruction, bowel, sexual and hormonal domains on 4-point or 5-point Likert scales, which was transformed to $0-100$ scores. Higher scores represent less severe symptoms and better health-related quality of life.

Psychological well-being

The General Health Questionnaire (GHQ-12) ${ }^{15} 16$ was used to assess psychological distress of men. The GHQ-12 
score ranges from 0 to 12 using the 0-0-1-1 scoring method; a higher score indicates a greater severity of psychological distress.

\section{General health behaviours}

The original version of the Godin Leisure-Time Exercise Questionnaire ${ }^{17}$ was used to evaluate health behavioural change of the men. The total weekly leisure-time physical activity score (Leisure Score Index (LSI)) was computed and a higher score indicates a higher level of leisure-time physical activity.

\section{Experience of care}

The National Cancer Control Indicators-Patient Experience Indicator (NCCI-PEx 1-8) is an 8-item questionnaire developed by Cancer Australia (unpublished work, 2017). The questions incorporate the Cancer Australia NCCI patient experience prioritised indicators and measures from the diagnosis and treatment domains of the framework. These prioritised indicators and measures are based on the Cancer Patient Experience Survey developed by the National Health Service in England, modified for use in the Australian context.

\section{Data analysis}

Reach, adoption and implementation of the intervention

Descriptive statistics were used to summarise data relating to recruitment, retention, utilisation of and compliance with intervention components, and the demographic and clinical characteristics of the men. For interview data, thematic analysis was performed by two researchers (RCo, W-HL) to identify the key perspectives of participants. This involved familiarising with the data, generating initial codes, searching for themes, reviewing themes, defining and naming themes, and summarising the findings. The third member of the research team (PY) checked the themes identified.

\section{Effectiveness of the intervention}

All subgroups completed the outcomes questionnaires at enrolment, 6 months and 12 months following enrolment. Therefore, data collected on these three time points were used in the analyses. Scales and subscales were constructed for each instrument following instrument developer's instructions. For each scale, if an individual respondent had half or more of the total items missing on any of the following scales, responses from the respondent were excluded from analyses related to that scale.

The study was not designed as a comparative effectiveness study, and as such no comparison group was included. Instead, we explored trends that might be of note to implementation of the intervention by comparing changes over time at three points on men's health outcomes. For all measures, data were analysed as a whole group. Subgroup analyses were also conducted according to the care pathway. To compare changes over time within a group/subgroup, one-way repeated-measures analysis of variance's were used if the outcome variables were continuous. Non-parametric tests (ie, Cochran's Q test) were performed if the outcome variables were categorical. All analyses were performed using SPSS for Windows (V.25.0). An alpha level of $\mathrm{p} \leq 0.05$ was considered statistically significant. Additionally, minimally important difference (MID) values were used to determine if changes in each domain of the EPIC measure were likely to be clinically relevant. The suggested MID for each domain of EPIC-26 were 6-9 points for urinary incontinence, 5-7 points for urinary obstruction/irritation, 4-6 points for bowel, 10-12 points for sexual, and 4-6 points for hormonal symptoms. ${ }^{18}$

\section{Patient and public involvement}

Patient representatives were consulted and involved in the development of the Australian TrueNTH programme. They were not involved in the evaluation study design, or analysis and interpretation of data, or writing of this manuscript.

\section{RESULTS}

\section{Reach of the intervention}

The flow of participants through different phases of the study is presented in figure 2. A total of 142 men and 59 carers participated in the study, representing a consent rate of $36 \%$. The intervention reached men across the five care pathways, with the largest groups being men who had completed treatment $(41 \%)$, followed by men with advanced disease $(24 \%)$. During the study, five men and three carers withdrew from the study. The main reasons for withdrawal included feeling no need for further services and support $(n=3)$, deteriorating health $(n=1)$, and privacy concerns $(n=1)$. One man died from prostate cancer and one carer died due to unrelated circumstances.

Of the 142 consented men, $127(89 \%)$ returned a completed baseline (T0) health outcome questionnaire, and $99(70 \%)$ and $92(65 \%)$ returned follow-up questionnaires at 6 months (T2) and 12 months (T4) following enrolment, respectively. A total of 80 men (56\%) returned questionnaires at all three time points.

Demographic and clinical characteristics of the men at enrolment are summarised in table 2. Around $40 \%$ $(\mathrm{n}=56)$ resided in major cities, $25 \%(\mathrm{n}=36)$ lived in inner regional areas and $35 \%(\mathrm{n}=50)$ resided in rural $/$ remote areas. About $45 \%(n=61)$ of the men were working full time/part time and $42 \%(\mathrm{n}=57)$ were retired. Compared with men who returned the questionnaire at 12 months, those who did not were significantly younger (mean age 67 vs 64 years old, $\mathrm{p}=0.04$ ), but not significantly different in terms of other demographic and clinical characteristics.

\section{Adoption of the intervention components}

The uptake of the TrueNTH services by the men during the study is summarised in table 3 . All men received an initial consultation with a TrueNTH care coordinator at enrolment. A central component of the intervention was the exercise and nutrition management services. The 


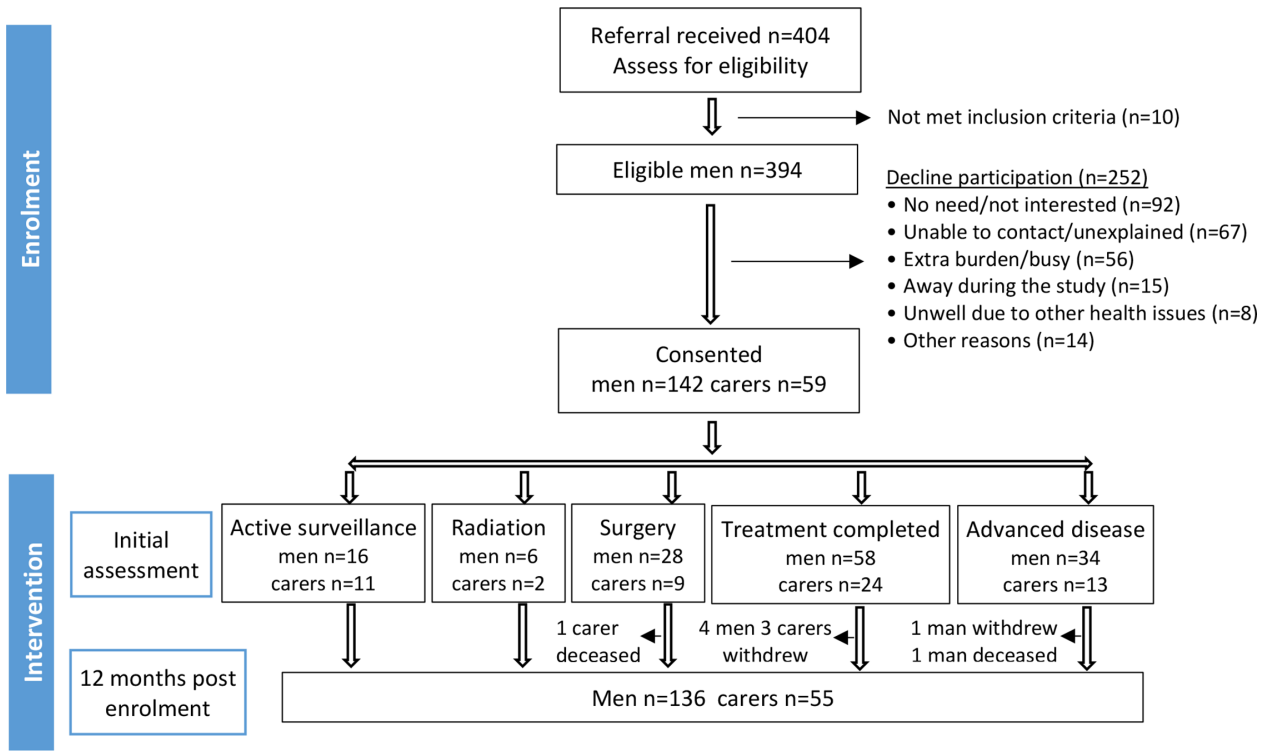

Figure 2 Flow diagram of recruitment and participation.

audit showed that $57 \%(\mathrm{n}=81)$ of the men were referred to both services, and $10 \%(n=14)$ were referred to one of these services following the initial consultation. About $10 \%(n=15)$ of the men who were under the care of a local care coordinator were referred back to the care coordinator, as per protocol. Another $22 \%(n=31)$ were referred to neither of the services and an explanation was recorded relating to the man's preferences and needs in 14 cases; but no explanation was provided in 17 cases. One man decided to withdraw from the study at the consultation as he felt he did not need any support from the programme. As a result, a total of 66 men participated in both nutrition and exercise interventions, 14 participated in the nutrition intervention only, and 23 participated in the exercise intervention only. A total of 39 participated in neither of these interventions. The main reason to decline participation in the exercise and nutrition interventions was lack of interest. Of the 89 men who participated in the exercise programme, 47 were provided by local services. However, only 5 of 80 men received nutrition interventions from local services. The proportion of men who participated in TrueNTH nutrition, exercise, psychosocial, continence and sexual health support did not differ by the care pathway (see online supplemental appendix 1).

\section{Effectiveness of the intervention}

\section{Prostate cancer-specific quality of life}

Mean scores and changes of men's prostate cancerspecific quality of life over the study period according to the care pathway are summarised in table 4. Overall, men consistently reported that the most severe bother was related to sexual function (with the lowest mean score), followed by urinary incontinence over the 12-month period. Given the absence of a comparison group our analysis is not intended to determine efficacy but rather to explore trends that may be of note to implementation of the intervention. It was observed that men in the treatment completed subgroup experienced statistically significant improvement in the hormonal domain over the study period.

The positive changes in the mean EPIC-26 hormonal and urinary incontinence scores met the threshold for MID in the treatment completed subgroup. Men in the surgery subgroup also reported positive and clinically relevant changes in the urinary incontinence and obstructive domains.

\section{Psychological well-being and general health behaviour}

Changes in psychological distress and total weekly leisuretime activity levels of the men according to the care pathway are presented in online supplemental appendix 2. Although we saw some evidence of reduced distress level and improved LSI score in men as a whole group, the changes were not statistically significant. Only men in the treatment completed subgroup had significantly improved in the LSI.

\section{Experience of care}

The proportion of men reporting satisfactory experience of the healthcare system during prostate cancer diagnosis and treatment is presented in online supplemental appendix 3. Overall, more men reported satisfactory experiences of the healthcare system for seven of eight statements at 12 months following enrolment in the intervention. However, only one improvement reached statistical significance, which was the proportion of men who were offered a written assessment and care plan.

\section{Implementation of the intervention}

A total of 18 men and five carers, 6 clinicians, 13 TrueNTH service providers and two Movember representatives participated in the interviews. A range of health system, intervention, healthcare provider and patient factors 
Table 2 Demographic and clinical characteristics of men $(n=142)$ at enrolment

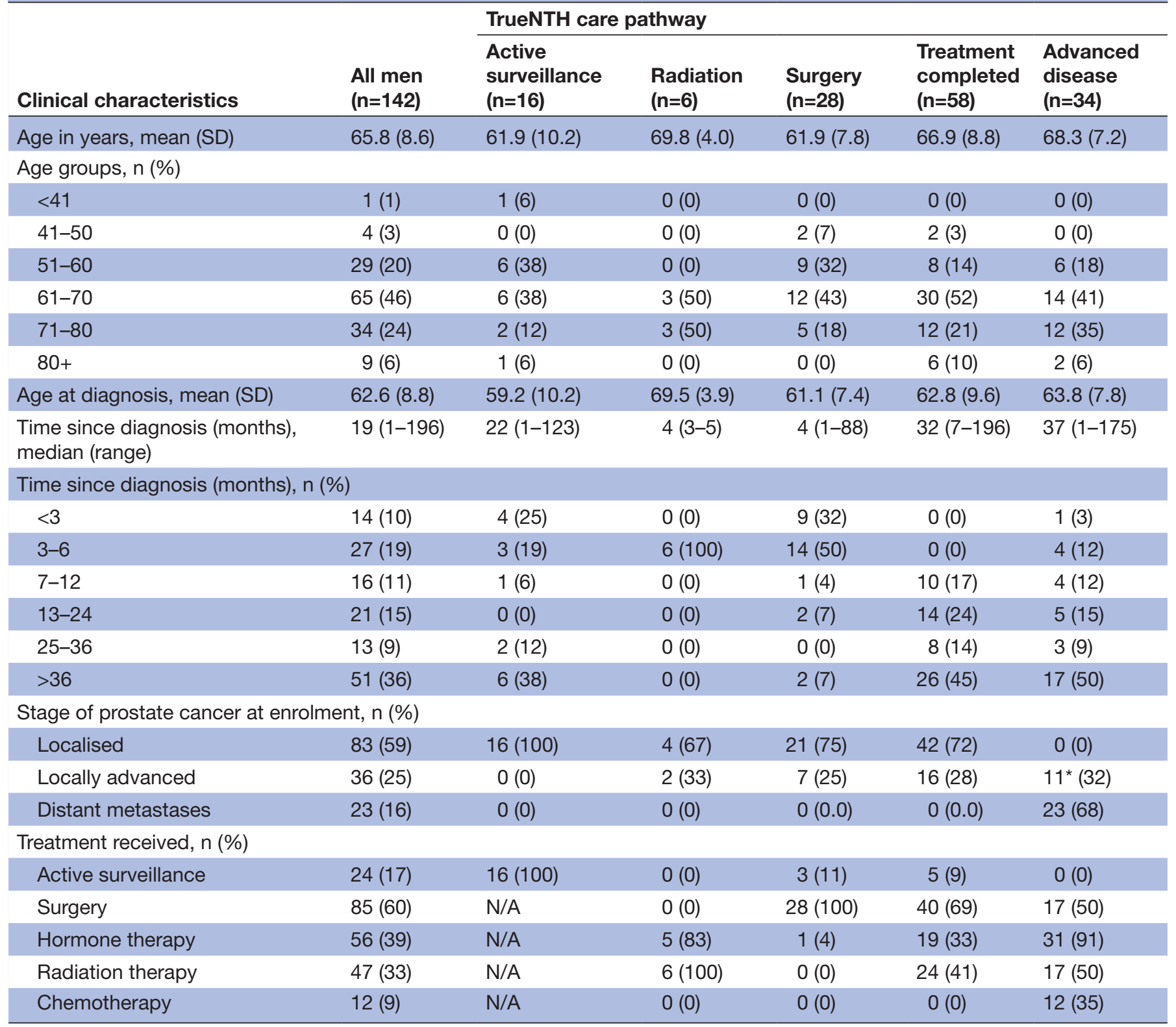

*With biochemical recurrence.

N/A, not applicable; SD, Standard deviation.

were identified as enablers and barriers to the successful implementation of the intervention. These factors with associated exemplar interview extracts are included in tables 5 and 6.

\section{DISCUSSION}

This is one of the only studies that have evaluated the implementation of multicomponent survivorship interventions for men with prostate cancer and their carers. The study questions were focused on implementation of the intervention and as such provides important insights into factors to be considered in implementing such approaches in this and other settings.
Overall, our findings were that while rates of enrolment in the study $(36 \%)$ were lower than anticipated, the intervention reached men at various stages of disease living across metropolitan, rural and remote areas. Men across all five care pathways participated in the intervention, with the largest group of participants being men who had completed treatment $(41 \%)$, followed by men with advanced disease (24\%). Over $60 \%$ of men were diagnosed more than 12 months before enrolment highlighting the importance of longer-term support for men with prostate cancer. Attrition from the programme was low, with $96 \%$ of participants completing 12 months of the programme. 
Table 3 Utilisation of the TrueNTH services over 12 months (total number of men=142)

\begin{tabular}{|c|c|c|c|c|c|c|c|}
\hline \multirow[b]{2}{*}{ TrueNTH services } & \multirow{2}{*}{$\begin{array}{l}\text { No of } \\
\text { participants } \\
\text { (\%) }\end{array}$} & \multicolumn{4}{|c|}{ No of episodes } & \multirow{2}{*}{$\begin{array}{l}\text { No of } \\
\text { episodes per } \\
\text { participant } \\
\text { Median } \\
\text { (range) }\end{array}$} & \multirow{2}{*}{$\begin{array}{l}\text { Length of } \\
\text { episodes per } \\
\text { participant } \\
\text { median (range } \\
\text { (in minutes) }\end{array}$} \\
\hline & & Total & Phone & Teleconference & Email & & \\
\hline $\begin{array}{l}\text { Care coordination (initial } \\
\text { consultation) }\end{array}$ & $142(100)$ & 142 & 142 & 0 & 0 & $1(1-1)$ & $60(10-130)$ \\
\hline Care coordination (follow-up) & $137(97)$ & 750 & 600 & 7 & 143 & $5(0-17)$ & $145(10-630)$ \\
\hline Nutrition support & $80(56)$ & 203 & 178 & 8 & 17 & $2(1-8)$ & $70(5-275)$ \\
\hline Exercise prescription & $89(63)$ & 356 & 280 & 1 & 75 & $2(1-17)$ & $35(2-184)$ \\
\hline Psychosocial support & $15(11)$ & 77 & 75 & 1 & 1 & $3(1-21)$ & $95(15-505)$ \\
\hline Sexual health & $10(7)$ & 28 & 22 & 0 & 6 & $2(1-6)$ & $145(60-270)$ \\
\hline Continence support & $9(6)$ & 22 & 22 & 0 & 0 & $2(1-5)$ & $45(7-70)$ \\
\hline
\end{tabular}

The main reasons for declining participation in this trial were no need for/no interest in support $(37 \%)$ and extra burden/being busy/away (28\%). The low rate of consent requires that we recognise the competing priorities of men and existing stressors when recruiting them to such interventions. This may require introducing components of the intervention at different time points and in flexible ways to accommodate men's readiness to participate in various aspects of the intervention as well as health literacy. Providing more information to men about the importance of managing late effects of prostate cancer and its treatment should be a priority.

Compared with population norms, ${ }^{19}$ the participants in this study were slightly younger at diagnosis. However, the wide age distribution of participants in this study confirms that supportive care interventions can be tailored to address age-related needs and concerns. Subgroup analyses conducted based on predefined care pathways highlighted the heterogeneity in patient characteristics and severity of bother associated with various care needs. Our evaluation is that programmes such as TrueNTH have great potential as they allow for tailoring of services to meet the specific needs of a diverse group of men living with prostate cancer. Keys to the success of this approach include comprehensive needs assessments, individualised care planning and care coordination delivered by healthcare professionals with specialised knowledge of prostate cancer.

Once enrolled in the study, uptake of general care coordination, exercise and nutrition management components of the intervention was high, and attrition was low. However, participation in various other components of the programme varied with only $11 \%$ receiving specialised psychosocial support, $7 \%$ sexual health support, and $6 \%$ continence management support, despite the high level of need recorded in the quality of life assessments of men in this study. The low uptake of these specialised services could be explained by a range of factors. First, low uptake may be due to the reluctance of care coordinators to refer patients to such services. That is, the local care coordinators were experienced nurses who may have felt they were able to meet these needs. Low uptake might also reflect reluctance on the part of participants to seek help for related concerns. One global general population study ${ }^{20}$ reported that less than $20 \%$ of men experiencing erectile difficulties sought help from a health professional. Men believed that the problem was not serious, and they were not bothered by the problem. Many men were also not aware of available treatments. Additionally, the actual rate of uptake of such services in this study may have been under-reported, as the service utilisation data collected were limited to the services provided by TrueNTH.

Variation in uptake of intervention components may also reflect variability in Care Coordinator approaches to implementation. Analysis of audit data relating to decisions about referral to exercise and nutrition interventions revealed that in the majority of cases, care coordinators applied the protocol consistently and where referrals were not made a sound explanation was provided relating to the individual man's preferences and needs. However, there were some cases where the reasons for deviation from the protocol were not explained. This lack of explanation could reflect limitations in record keeping. It could also reflect some unexplained variation in how individual care coordinators deliver their care.

The single group pre-post evaluation design used for this study means that it is not possible to definitively conclude that the TrueNTH programme led to statistically significant improvements in outcomes for men. Nonetheless, the multiple sources of data collected as part of this evaluation provide support for continuing to build on the principles and components of the TrueNTH model. Overall, men reported some improvements in their experience of care. Men were also more likely to engage in exercise-based interventions. These changes in patient reported outcome measures over time provide some evidence that the programme has the potential to deliver important benefits for men.

The design of this study based on the RE-AIM framework $^{12}$ also identified some important enablers and 


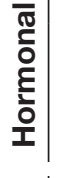

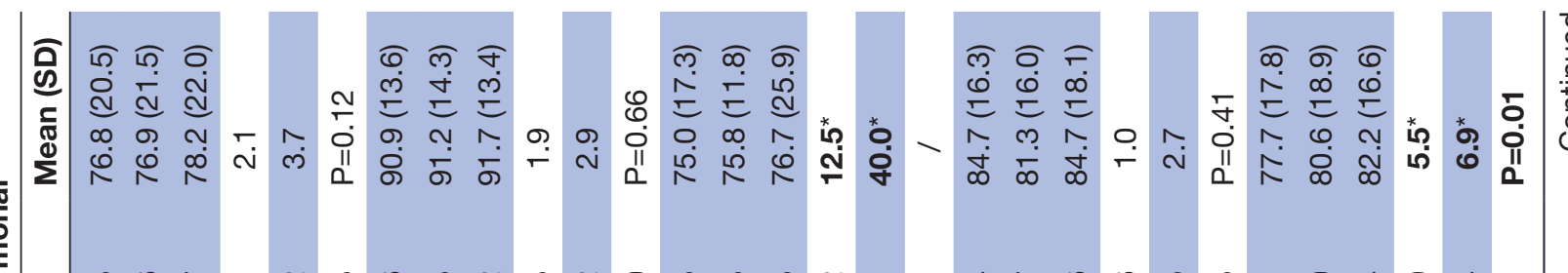

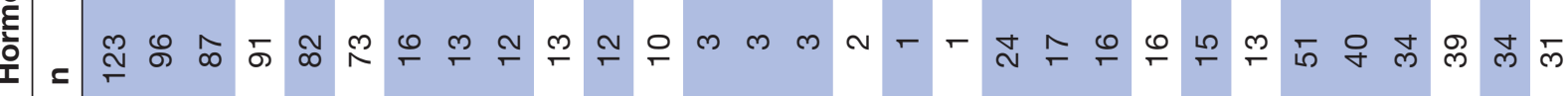

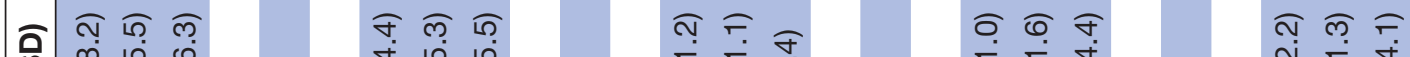

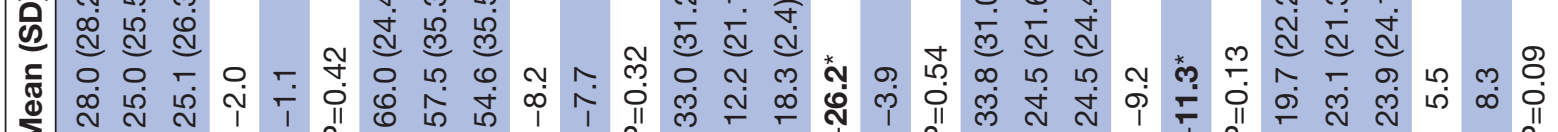

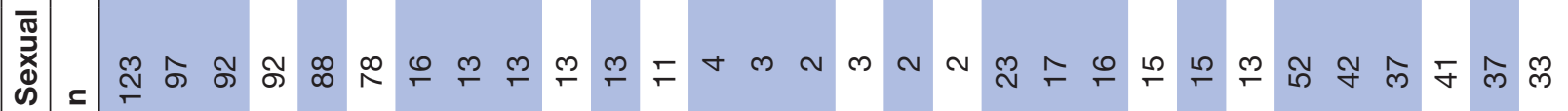

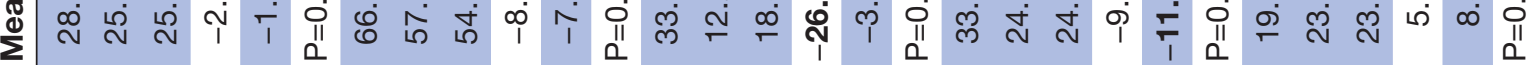

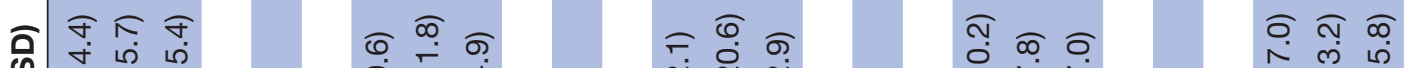

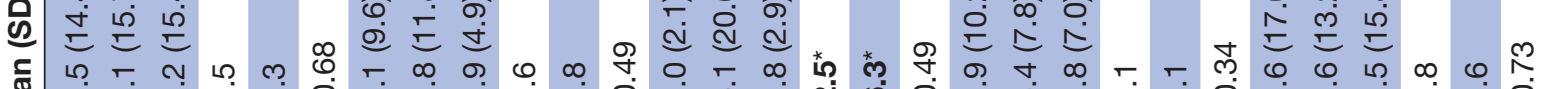

幽

勿

:

幽

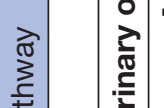

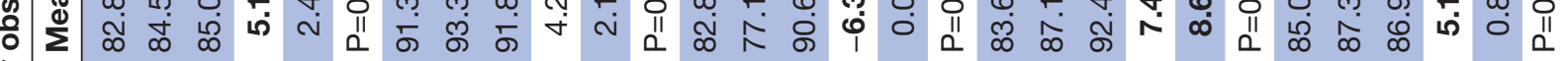

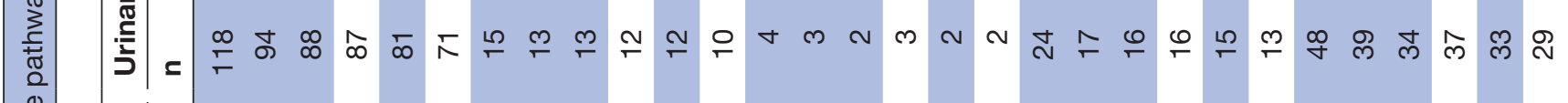

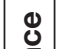

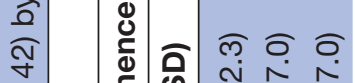

$\widehat{ก} \approx$

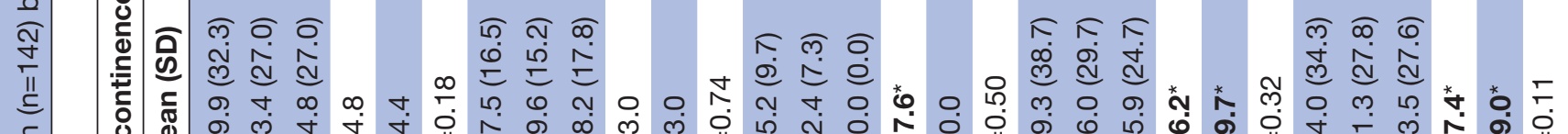

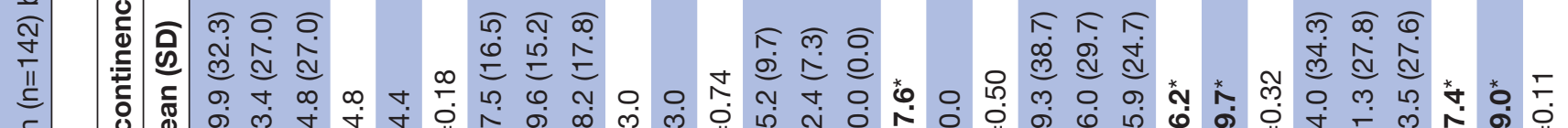

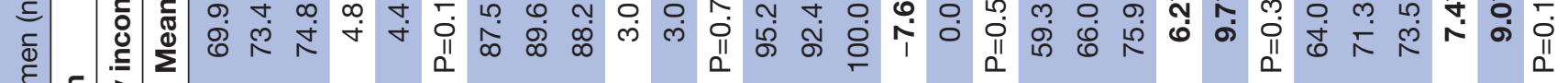
离

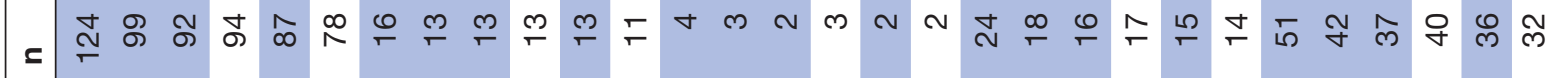

:

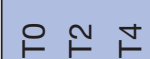

$\stackrel{\vdash}{\vdash}$

요만

윰

$\stackrel{\sim}{\vdash} \Vdash$

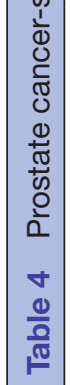<smiles>C1CCC1</smiles>

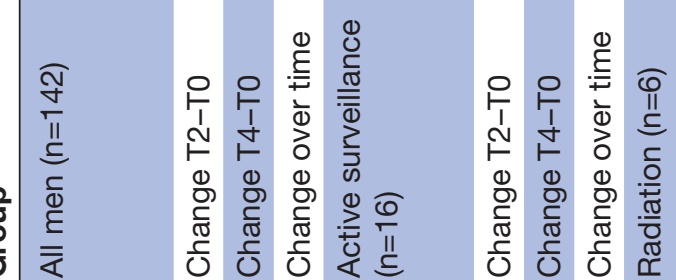
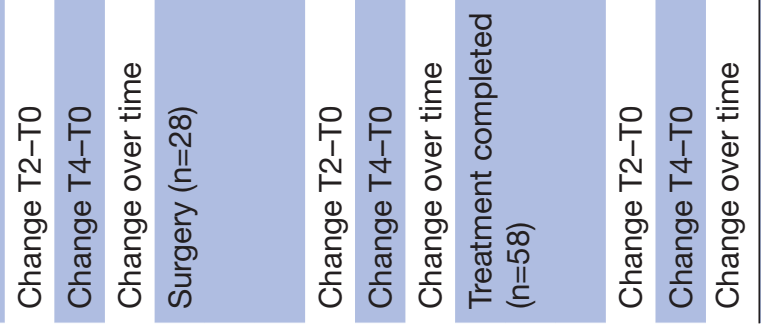


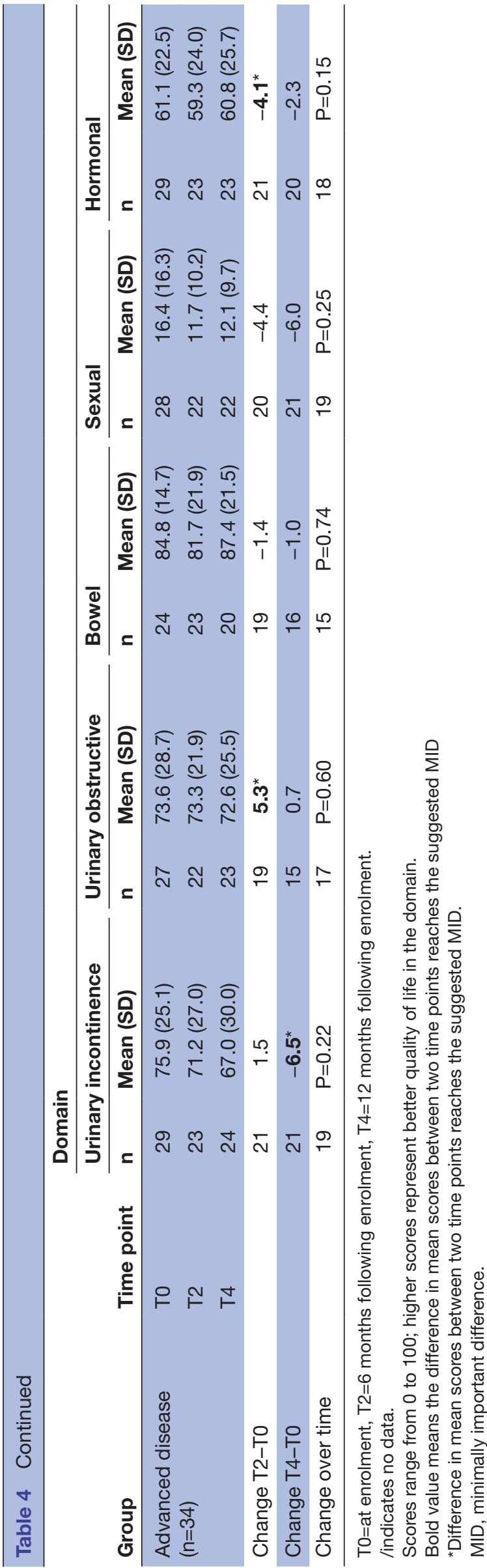

barriers to implementation of the programme in the participating settings. These factors were at the health system, intervention, healthcare professional and patient level, and provide important information to guide the successful development and implementation of complex interventions. In particular, the enablers and barriers to use of the technology-based features of the intervention can inform future developments in digital innovations in healthcare, as the demands increase for such advances in the healthcare system. The importance of coordination of care across service providers was also highlighted as the success of the model was dependent on capacity of the service to engage in recruitment of participants and TrueNTH activities, as well as the extent to which the TrueNTH model was integrated with existing services such as specialist prostate cancer nurses and multidisciplinary teams.

\section{Implications for practice}

Through this study, we have revealed new evidence to guide future implementation of TrueNTH and similar programmes. Specifically, findings from this study highlight that survivorship care interventions are relevant to men at all stages of disease and treatment plan. Survivorship care interventions for men with prostate cancer and their carers should therefore continue to incorporate principles that enable risk stratification, tailoring of services to individual needs and optimisation rather than duplication of existing service capacity. We have established that it is possible to provide access to a comprehensive model of survivorship care, including a focus on improving exercise and nutrition behaviours to promote health and quality of life for men. The delivery of such interventions by telehealth should continue where required, with additional efforts to upskill relevant care providers across a broader range of settings. This requires ongoing use of standardised needs assessment tools and regular service capability assessments, as well as more formalised partnership agreements and protocols about the roles and responsibilities of various service providers. Strategies are also required to enable a greater focus on addressing barriers associated with referral to and uptake of specific services such as psychological support and sexual counselling. Moreover, survivorship interventions require care coordination strategies that underpin the intervention to manage the multiple service providers required to meet the needs of men, including maintaining a single point of contact, and use of shared assessment and care planning tools.

This intervention incorporated a range of important digital technologies to enable reach, uptake and effectiveness, including a web based shared care plan as well as telehealth delivery. While the telehealth approaches were widely accepted and resulted in broad reach, the digital care planning platform was not as widely used outside of the TrueNTH clinical team. While the platform was critical to sharing of information across the team, future platforms should draw on available evidence about effective 
Table 5 Programme enablers

\section{Health system factors}

Addressing service gaps I think you know that's largely why this is in place because a lot of the men are in rural areas. So I and extending service think in that setting it's very helpful. Pretty rare to get a psychiatrist or psychologist service on the provision phone. So in that sense like it's sort of highly unique in Australia. (TNSP8) There are definite gaps in service provision for men and their families with prostate cancer.

Particularly you know men who don't live in metropolitan cities. However, you know I even think that men who do live in metropolitan cities don't always have access to great care either. You know you can access care as an inpatient very easily but as soon as you become an outpatient it becomes a very difficult thing to do. And so you know I think that TrueNTH fits really well into those gaps. (TNSP1)

Once again a lot of our patients that we see I don't think they are followed up with some of their needs. They're told they have cancer, they have surgery, and they're shoved along, come back in however many months for your next appointment, but there's not any more assistance for them. (Clinician4)

Providing specialised services

In the public hospital I don't think we've ever had anything for the patients like it before, so we've never been able to follow up with their incontinence or unless they've come back through clinic. But there's never been anything like that or exercise they haven't had these program available to them before, so I think it's just better options for people, better opportunities. (Clinician4)

$\begin{array}{ll}\text { Supporting carers } & \text { We pick up that there might be issues with the partner's distress and grief. But often feel our hands } \\ \text { are tied as to what you can actually do for the partners. So I thought that was excellent support for } \\ \text { carers and partners that I felt that perhaps I couldn't offer as well. (Clinician6) }\end{array}$

Intervention related factors

Needs-based approach I think that TrueNTH is able to tailor to that, we're able to give very personalised, individualised care. (TNSP1)

Each person wants a different level of support and I think too, the thing with this particular cohort is some of them want quite a lot of support, others you'll give them a defined meal plan and it makes sense to them, they'll do it from today until the rest of their life they'll just keep doing it and don't need much so they're very, they know themselves by this stage in life, very open and honest as a group to communicate with so, you will generally find, as I said before if we get our first contact right then we're likely to have a reasonable impact. (TNSP6)

Telehealth based When I first started with TrueNTH I was a little bit sceptical about whether I could develop the same approach rapport and provide the same support over, doing it as a telehealth service. But after working in the clinic, I was there for eight years, so doing it in a physical sense and I'm now doing it as a telehealth sense. There's really no difference, I feel that I'm actually supporting these guys as well as I was working face to face. (TNSP3)

Care coordination

There's the importance of having a skilled and knowledgeable coordinator who knows how to engage with both GPs and specialists is pretty key to this type of programme. I think that it needs to have to be able to build that trust with the specialist that the person is not lost in any particular when they're getting some kind of shared care with the GP. (M1)

I think the TrueNTH staff were available if you needed help or if you wanted clarification and I think they were diligent in their duties and support. (Clinician6)

Healthcare provider factors

Specialist expertise of TrueNTH team
Skilled clinicians is what the program sits on, whether it's the exercise physiology or xx being dietician or the care coordinators, the commonality is our high levels of communication skills. (TNSP4)

I think the TrueNTH program, it, to me it was more, it was more important to have somebody to talk to at my level, more so than anything, you know? So, it was more helpful in that respect, to me.... like you guys were more helpful, and this is nothing against the Doctors or anything.... I think you guys were more helpful, than the Doctors at the hospital. (Patient47)

I think all of the fields of expertise that were offered to me were really very well handled. They were people who knew what they were talking about and they were all a great help. (Patient66)

M, Movember representative; TNSP, TrueNTH service provider.

technology enabled interventions to support its application in survivorship care, while maintaining flexibility to respond to varying levels of technological literacy among consumers and healthcare providers. The COVID-19 pandemic and subsequent pivoting to telehealth has greatly advanced health professionals' familiarity with using digital technologies across Australia at the same time that all age groups in the Australian community have 
Table 6 Programme barriers

\section{Intervention related factors}

Limitations of The most difficult one is penile rehabilitation and the sexual rehabilitation and that's really hard to do by

telehealth-based distance. (Clinician1)

approach

For example there might be a man who is quite advanced and for example if they've got ... quite expansive skeletal metastases I'm not usually comfortable with providing them a home based program, I don't want them to exercise unsupervised. So I won't provide that person with a program he can do on his own .... And then I like toss-up between is he going to be better off just doing it unsupervised or should I be sticking to no it's not really safe for him to do it unsupervised? That can be tough in that situation. (TNSP5)

Insufficient resources and high caseload
Definitely needing to ensure dedicated, not just diary space or ... but also physical space. I've always never been a fan of sort of open plan offices. That's an impediment I think to sort of free-flowing interactions with patients.... So personal preference would be a room with dedicated access on that afternoon with a camera. That would be good I think that would hopefully diminish the intrusion of other demands, that requires widespread team sort of structure. (TNSP8)

Time restraints has been tough .... You go through phases where you are getting a large number of referrals and each new referral is a significant amount of time on that individual. And when you're getting a fair few coming through at the same time it can be quite tough. Time and then when you're also including all these new referrals and you're trying to service as quickly as you can. If you've got a schedule to follow up you're organising at the same time. So things can fall behind, just even on track with time and that sort of thing has been fairly difficult. (TNSP5)

Insufficient It felt that we had to continually remind them. So even though this is a big teaching hospital with you know integration with very good history of .... And possibly because of that everybody's time and focus is so you know you have existing services to keep reminding them that you're there, that you're present. And keep reminding them of the program. (Clinician6)

Trying to gain momentum and support from nursing colleagues to deliver TrueNTH has been more difficult than any other of the you know clinical fields. Just because there's been a perceived threat to the work that they're already doing. (TNSP1)

I think the confused support from $x x$ was a significant issue. We had mixed messages from their executives to their nursing management, lack of support through the $x x$ and their direct manager making it difficult to have a working relationship and make the program work well in those settings where there was a prostate cancer specialist nurse. So that was a problem the whole way through that was really difficult to navigate and continues to be in that space. (M1)

In the times we attempted to get them engaged with local services, we found it took just as long to try to get them to engage with local services and then more often than not they wouldn't engage with the local service. (TNSP6)

Healthcare provider factors

Quality of team l'd like it if there was better communication or integration between the clinicians, which cdmnet is not communication doing. Because it feels like to me once the care coordinator refers to us then it's, like I said before there's no feedback or overview. It feels like I can't, when I feedback, I don't know if it's been accepted, I mean read, unless I prompt them.... You're supposed to go back to the GP, people are trained to go back to their GP who coordinates everything. And if that's the care coordinator then fine, but somehow the care coordinator still has to extract themselves out of the systems once it's done so they still have to go back to the GP or the Specialist, and that bit I felt, that's never been clear to me that that is being done nicely. (TNSP7) $X$ said she didn't get a feedback from one of the case managers, that was, the guys was quite upset that he hadn't been contacted back by the case manager... I think he needs a geriatrician review; I mean I did have a look back at the notes to see what was done. (TNSP9)

Lower priority to We are very, very busy clinics and sometimes you just don't have time with every prostate cancer patient supportive care issues
... To actually sit down with the guys individually and have a good chat about the project was probably a challenge for us.... But as I say just because of the sheer numbers we see and also we have kind of quite a lot of registrars and junior staff who are changing over quite frequently, who probably weren't aware of all... all the staff of our unit weren't aware of the program. So really I was the main one pushing for it and quite a lot of the other staff they just needed constant reminders and things. (Clinician3)

Although now (supportive care) is more accepted and we want to do it, it's still a little bit foreign to many of the stakeholders that we would engage with. And particularly some medical specialists. You know they're very focussed on oncological care and so providing supportive care you know around lifestyle and mental health and sexual dysfunction is not something that they would ordinarily put in their practice. (M2) 
Table 6 Continued

Perceptions of relevance of the service

You get things like people don't have the time, a lot of, especially with this demographic, they don't see the need for exercise. This is probably the main one is that feel, they basically don't see the need. One is that they don't care for exercise and they don't see a reason to do it, I guess the benefits of exercise is still a fairly new theory I guess, a new kind of treatment if you like. So a lot of the demographic that we look after just don't see the benefit for it and don't see why there's a need. (TNSP5)

Some guys didn't feel that they needed the service. Your typical you know rural, remote guy that doesn't like talking to people that sort of stuff. It was more the personality that was probably more the barrier than anything else. (TNSP4)

Reluctance to discuss needs

I don't want to be a grizzler.... He (TrueNTH care coordinator) rings up and I'll tell him okay l'll probably say yeah all good I'm doing alright. So I'm just not quite sure how much TrueNTH is aware of the bladder infections and the bowel complications and all that sort of stuff. I don't think that I've communicated that. (Patient34)

Well it's hard because not, blokes don't talk about what their problems are. Where I live here you know like we've got a very close social group and that sort of thing and in the men there's probably half a dozen that have got similar problems to what l've got. But they're not interested in doing anything about it. They don't want to join a group or they just go to there have their tests and things done and they don't sort of worry about it that much you know. (Patient51)

Reluctance/lack It's not something I've used, not a lot of ... I think there's only been one of my guys that has wanted to use of confidence the video, they're all quite happy with the phone calls. (TNSP3)

with technology We are very naïve with the ... we really don't have a computer. I know it would be wonderful (video call) if I could do it but I just, I go into a bit of a panic when there's something new and I can't remember everything I'm supposed to do. (Carer126)

For me personally, I like face to face. So it's a bit hard for me to answer that because talking to somebody on the phone is great but then you get off the phone and you know. So it's a personal thing I guess really, what each person reacts to and as I said I'm more a face to face person. (Carer80)

M, movember representative; TNSP, TrueNTH service provider.

embraced the use of digital technology into their dayto-day social communication and acceptance of and familiarity with telehealth platforms is now greatly increased from when this study was conducted. The success of the TrueNTH model, therefore, provides great promise for the future.

\section{Author affiliations}

${ }^{1}$ Cancer and Palliative Care Outcomes Centre, Queensland University of Technology Faculty of Health, Kelvin Grove, Queensland, Australia

${ }^{2}$ Deakin Health Economics, Institute for Health Transformation, Deakin University Faculty of Health, Geelong, Victoria, Australia

${ }^{3}$ Movember, Richmond, Victoria, Australia

${ }^{4}$ Dixon Healthcare Consulting, Melbourne, Victoria, Australia

${ }^{5}$ Exercise Medicine Research Institute, Edith Cowan University, Joondalup, Western Australia, Australia

${ }^{6}$ School of Human Movement and Nutrition Sciences, The University of Queensland, Saint Lucia, Queensland, Australia

${ }^{7}$ Institute for Physical Activity and Nutrition, School of Exercise and Nutrition Sciences, Deakin University, Burwood, Victoria, Australia

${ }^{8}$ Private Practitioner, Sunshine Coast, Queensland, Australia

${ }^{9}$ Department of Psychiatry, School of Clinical Sciences at Monash Health, Monash University Faculty of Medicine, Nursing and Health Sciences, Melbourne, Victoria, Australia

${ }^{10}$ Centre for Cancer Research, Department of General Practice, The University of Melbourne, Melbourne, Victoria, Australia

${ }^{11}$ Department of Surgery, Cabrini Institute, Cabrini Health, Monash University Faculty of Medicine, Nursing and Health Sciences, Melbourne, Victoria, Australia

Twitter Nicolas Hart @DrNicolasHart and Brenton Baguley @brenton_james1

Acknowledgements We thank all of those who participated in this research, particularly the TrueNTH care coordinators, participating sites and TrueNTH specialist support service providers. Special thanks to the men and their caregivers for their effort in participating in this study.
Contributors PY and RCa obtained funding from Movember and led the study. PY, $\mathrm{RCa}, \mathrm{RC} 0, \mathrm{DC}, \mathrm{CD}, \mathrm{AL}, \mathrm{RUN}, \mathrm{NH}, \mathrm{DAG}, \mathrm{BB}, \mathrm{ND}, \mathrm{TS}, \mathrm{JC}, \mathrm{JE}, \mathrm{MF}$ and W-HL contributed to the conception or design of the study, or acquisition of data, or analysis and interpretation of data. PY and W-HL drafted the manuscript. All authors contributed to critical revision of the manuscript and approved the final version. PY is the guarantor of this paper.

Funding TrueNTH is funded by Movember (no award/grant number), a global charity organisation committed to the improvement of health outcomes for men living with prostate cancer, as well as supporting men with testicular cancer and programmes focused on suicide prevention and mental health. $\mathrm{NH}$ is supported by a Cancer Council of Western Australia Postdoctoral Research Fellowship.

Competing interests $\mathrm{DC}$ and $\mathrm{CD}$ were employees of Movember during the study. CD was the Project Manager and DC was a central care coordinator of the TrueNTH programme. ND was a private practitioner who provided dietetic service in the programme.

Patient consent for publication Not applicable.

Ethics approval This study involves human participants and was approved by the human research ethics committees of participating health services (Austin Health HREC/16/Austin/436, Northern Territory Department of Health and Menzies School of Health Research 2017-2769, Central Australian CA-17-2785, Edith Cowan University 17389) and the coordinating universities (Queensland University of Technology 1600001160 and Deakin University 2017-002).

Provenance and peer review Not commissioned; externally peer reviewed.

Data availability statement Data are available on reasonable request. The datasets used and/or analysed in this study are available from the corresponding author on reasonable request.

Supplemental material This content has been supplied by the author(s). It has not been vetted by BMJ Publishing Group Limited (BMJ) and may not have been peer-reviewed. Any opinions or recommendations discussed are solely those of the author(s) and are not endorsed by BMJ. BMJ disclaims all liability and responsibility arising from any reliance placed on the content. Where the content includes any translated material, BMJ does not warrant the accuracy and reliability of the translations (including but not limited to local regulations, clinical guidelines, terminology, drug names and drug dosages), and is not responsible 
for any error and/or omissions arising from translation and adaptation or otherwise.

Open access This is an open access article distributed in accordance with the Creative Commons Attribution Non Commercial (CC BY-NC 4.0) license, which permits others to distribute, remix, adapt, build upon this work non-commercially, and license their derivative works on different terms, provided the original work is properly cited, appropriate credit is given, any changes made indicated, and the use is non-commercial. See: http://creativecommons.org/licenses/by-nc/4.0/.

\section{ORCID iDs}

Patsy Yates http://orcid.org/0000-0001-8946-8504

Robert U Newton http://orcid.org/0000-0003-0302-6129

Daniel A Galvão http://orcid.org/0000-0002-8209-2281

Jon Emery http://orcid.org/0000-0002-5274-6336

Wei-Hong Liu http://orcid.org/0000-0002-1241-517X

\section{REFERENCES}

1 Australian Institute of Health and Welfare. Cancer in Australia 2019. Cancer series no.119. Cat. No: CAN 123. Canberra: AlHW, 2019.

2 National Cancer Institute Surveillance, Epidemiology, and End Results (SEER) Program. SEER Cancer Statistics Review 1975-2017. Available: https://seercancergov/csr/1975 2017/results merged/ sect_23_prostatepdf\#search=prostate\%20cancer [Accessed May 2020].

3 Cancer Research UK. Available: https://wwwcancerresearchukorg/ health-professional/cancer-statistics/statistics-by-cancer-type/ prostate-cancer\#heading-Two [Accessed May 2020].

4 Paterson C, Robertson A, Smith A, et al. Identifying the unmet supportive care needs of men living with and beyond prostate cancer: a systematic review. Eur J Oncol Nurs 2015;19:405-18.

5 Hoffman KE, Penson DF, Zhao Z, et al. Patient-Reported outcomes through 5 years for active surveillance, surgery, brachytherapy, or external beam radiation with or without androgen deprivation therapy for localized prostate cancer. JAMA 2020;323:149-63.

6 Carlsson S, Drevin L, Loeb S, et al. Population-Based study of longterm functional outcomes after prostate cancer treatment. BJU Int 2016;117:E36-45.
7 Parahoo K, McDonough S, McCaughan E, et al. Psychosocial interventions for men with prostate cancer: a Cochrane systematic review. BJU Int 2015;116:174-83.

8 Yates P, Liu W-H, Dixon C. Taking action to improve outcomes for men living with and beyond prostate cancer. Aust Nurs Midwifery $J$ 2016;24:35.

9 NHS Improvement. Effective follow up: testing risk stratified pathways, 2011. Available: wwwimprovementnhsuk/cancer/ survivorship

10 Clinical Oncology Society of Australia Model of Survivorship Care Working Group. Model of survivorship care: critical components of cancer survivorship care in Australia position statement. Clinical Oncology Society of Australia, 2016.

11 Yates P, Carter R, Cockerell R, et al. An integrated multicomponent care model for men affected by prostate cancer: a feasibility study of TrueNTH Australia. Psychooncology 2021;30:1544-54.

12 Glasgow RE, Vogt TM, Boles SM. Evaluating the public health impact of health promotion interventions: the RE-AIM framework. Am J Public Health 1999;89:1322-7.

13 Arends J, Bachmann P, Baracos V, et al. ESPEN guidelines on nutrition in cancer patients. Clinical Nutrition 2017;36:11-48.

14 Wei JT, Dunn RL, Litwin MS, et al. Development and validation of the expanded prostate cancer index composite (EPIC) for comprehensive assessment of health-related quality of life in men with prostate cancer. Urology 2000;56:899-905

15 Goldberg DP, Gater R, Sartorius N, et al. The validity of two versions of the GHQ in the who study of mental illness in general health care. Psychol Med 1997;27:191-7.

16 Goldberg D, Paul W. A user's guide to the General Health Questionnaire. London: GL Assessment, 2006.

17 Godin G. The Godin-Shephard leisure-time physical activity questionnaire. The Health \& Fitness Journal of Canada 2011;4:18-22.

18 Skolarus TA, Dunn RL, Sanda MG, et al. Minimally important difference for the expanded prostate cancer index composite short form. Urology 2015;85:101-6.

19 Australian Institute of Health and Welfare. Cancer compendium: information and trends by cancer type. Cat. No: CAN 119; prostate cancer (C61). Canberra, ACT: AlHW, 2018.

20 Moreira ED, Glasser DB, King R, et al. Sexual difficulties and helpseeking among mature adults in Australia: results from the global study of sexual attitudes and behaviours. Sex Health 2008;5:227-34. 